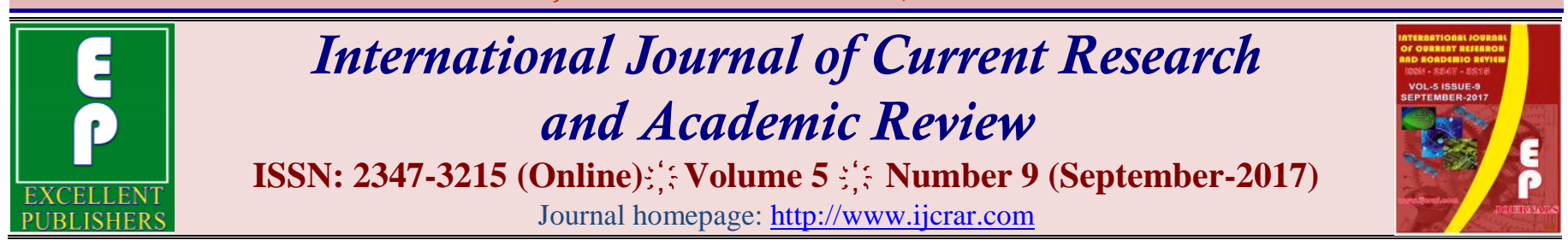

doi: https://doi.org/10.20546/ijcrar.2017.509.003

\title{
A Prospective Randomised Trial to Study the Efficacy of Vitamin B6 (Pyridoxine) and Vitamin E in Patients of Premenstrual Syndrome
}

\author{
Shikha Singh, Rekh Rani, Asha, Ragini and Divya Yadav Sharma*
}

S N Medical College Agra, Uttar Pradesh, India

*Corresponding author

\section{Abstract}

The present study was focused on to randomised trial to study the efficacy of Vitamin B6 (Pyridoxine) and Vitamin E in Patients of Premenstrual Syndrome. A total of 90 females of age group 17-25 years with premenstrual symptoms(psychological or somatic), fulfilling the ICD-10 and DSM-IV criteria were randomly allocated into three groups A,B,C having 30 subjects in each group. During this study it was found that there was the symptom score of group A and B has significant reduction over group C, hence it is beneficial to give vitamin E and B6 for reducing the symptoms of premenstrual syndrome over placebo treatment. Results for comparison in groups $\mathrm{A}$ and B were insignificant. Vitamin E and B6 were equally effective for the improvement in symptoms of premenstrual syndrome.
\end{abstract}

\section{Article Info}

Accepted: 25 August 2017

Available Online: 20 September 2017

\author{
Keywords \\ Vitamin B6 (Pyridoxine), \\ Vitamin E, \\ Premenstrual Syndrome
}

\section{Introduction}

Premenstrual syndrome is a common cyclical disorder of young and middle aged women and is characterized by emotional and physical symptoms that consistently occur during the luteal phase of menstrual cycle. Symptoms can be severe enough to disrupt everyday life. Mild physiological symptoms arise in almost $95 \%$ of all women of reproductive age. Nearly $5 \%$ of symptomatic women complain of completely disrupted everyday life. ${ }^{1}$ Somatic symptoms of premenstrual syndrome include bloating, weight gain, tenderness of breast, abdominal discomfort, fatigue, headache.

Frequently reported affective fluctuations are dysphoria, irritability, nervousness, tension, and aggression. ${ }^{2}$ Till date the pathogenesis remains unclear and speculative. ${ }^{3}$ Most interventions, however, based on informal observations, retrospective studies, ornon controlled trials. The role of some vitamins like Vitamin B6 and Vitamin E also documented. The efficacy of vitamin B-6 and Vitamin $\mathrm{E}$ has not yet been proved in women with premenstrual syndrome. This study was conducted to compare the improvement of symptoms in subjects given Vitamin E, Vitamin B6 supplementation, and placebo therapy during premenstrual period

\section{Materials and Methods}

The study was carried out in the Department of Obstetrics and Gynecology S N Medical College Agra in the year 2014-2015.

A total of 90 females of age group 17-25 years with premenstrual symptoms(psychological or somatic), fulfilling the ICD-10 and DSM-IV criteria wererandomly allocatedinto three groups A,B,C having 30 subjects in 
each group. From $16^{\text {th }}$ day of the menstrual cycle up to the start of next menstrual period:

Group A was given vitamin E- 400mg

Group B -100 mg pyridoxine,

Group C- placebo tablets

All these 90 patients were given a questionnaire based on premenstrual symptoms (Weight Gain, Generalized Swelling, Acne, Breast Tenderness, Abdominal Bloating, and Mood Changes) and their severity (No Symptoms-0; Mild-1; Moderate-2; Severity-3). A relevant history and informed consent were obtained. All the three groups were assessed based on their symptom scores. The symptom score was measured at the start of supplementation and then after the supplementation at the end of $1^{\text {st }}, 3^{\text {rd }}$ and $6^{\text {th }}$ month and the change in symptoms were also assessed on the basis of the questionnaire. All the patients in the three groups were comparable regarding, Age, Age of menarche, working status, Education, and Parity.

\section{Results and Discussion}

\section{Weight Gain}

The Vit-E grouphas been shown asignificant $71 \%$ reduction (initial 45 to 13 at $6^{\text {th }}$ month) in weight gain score. Similarly, a 38\% reduction in scores of weight gain in Vit-B6 group (initial 52 to 32 at $6^{\text {th }}$ month) was also observed at $6^{\text {th }}$ month but not as marked as in Vit-E group.

\section{Headache}

The headache scores observed with a marked and gradual reduction in Vit-E and Vitamin-B6 groups in comparison to placebo, $70 \%$ and $67.6 \%$ at $6^{\text {th }}$ month respectively.

\section{Generalised Swelling}

No Significant reduction in scores of generalized swelling except Vit-E group at $6^{\text {th }}$ month $(60 \% ; 35$ to 14$)$ was observed.

\section{Breast Tenderness}

A marked and gradual reduction in scores for Tenderness of breast has been observed in both Vit-E and VitaminB6 groups in comparison to placebo, 86\% (51 to 7) and
$67 \%$ (46 to 15 ) at $6^{\text {th }}$ month respectively in comparison to placebo.

\section{Acne}

A marked and gradual improvement in scores for Acne has been observed in Vit-E group $(80 \% ; 23$ to 5 ) in comparison to placebo $(33 \% ; 18$ to 12$)$ but not in Vit-B6 group $(11 \% ; 46$ to 15$)$ at $6^{\text {th }}$ month.

\section{Abdominal Bloating}

Improvement in abdominal bloating scores found to be more pronounced in Vit-B6 group (54.8\%; 62 to 28$)$ than Vit-E $(27.2 \% ; 52$ to 41$)$ group in comparison to placeboat $6^{\text {th }}$ month.

\section{Mood Changes}

Improvement in abdominal bloating scores found to be more pronounced in Vit-B6 group (46\%; 43 to 23 ) than Vit-E $(4 \% ; 45$ to 42$)$ group in comparison to placebo (23\%; 51 to 39$)$ at $6^{\text {th }}$ month. Even Vit-E found not better than placebo.

Current study suggested that Vitamin E and Vitamin B6 improve the mean score of various symptoms of PMS as reflects in result section and there are some other RCTs which are also showing some similar kind of results.

A meta-analysis of Nine published trials representing 940patients with premenstrual syndrome suggests that doses of vitamin B-6 up to $100 \mathrm{mg} /$ day are likelyto be of benefit in treating premenstrual symptomsand premenstrualdepression. ${ }^{4}$ Results from 4 RCTs with doses of vitamin B-6 up to $100 \mathrm{mg} /$ daywere conflicting, 3 RCTs suggested Improved premenstrual depression and irritability in very few patients, but these were very small sample size studies and third one suggested no improvement better than placebo. $\mathbf{5 , \mathbf { 6 , 7 }}$

In contrary to that one RCT where $150 \mathrm{mg} /$ dayof vitamin B-6 used suggested that beneficial effect of pyridoxine seen on autonomicand behavioral symptoms, with no effectobserved on depression and anxiety. ${ }^{9}$ With larger doses like $500 \mathrm{mg} /$ day of vitamin B6 Improvement in total premenstrual symptoms in 21 subjects on pyridoxine out of 25 patients treated with vitamin B6. ${ }^{10}$ 


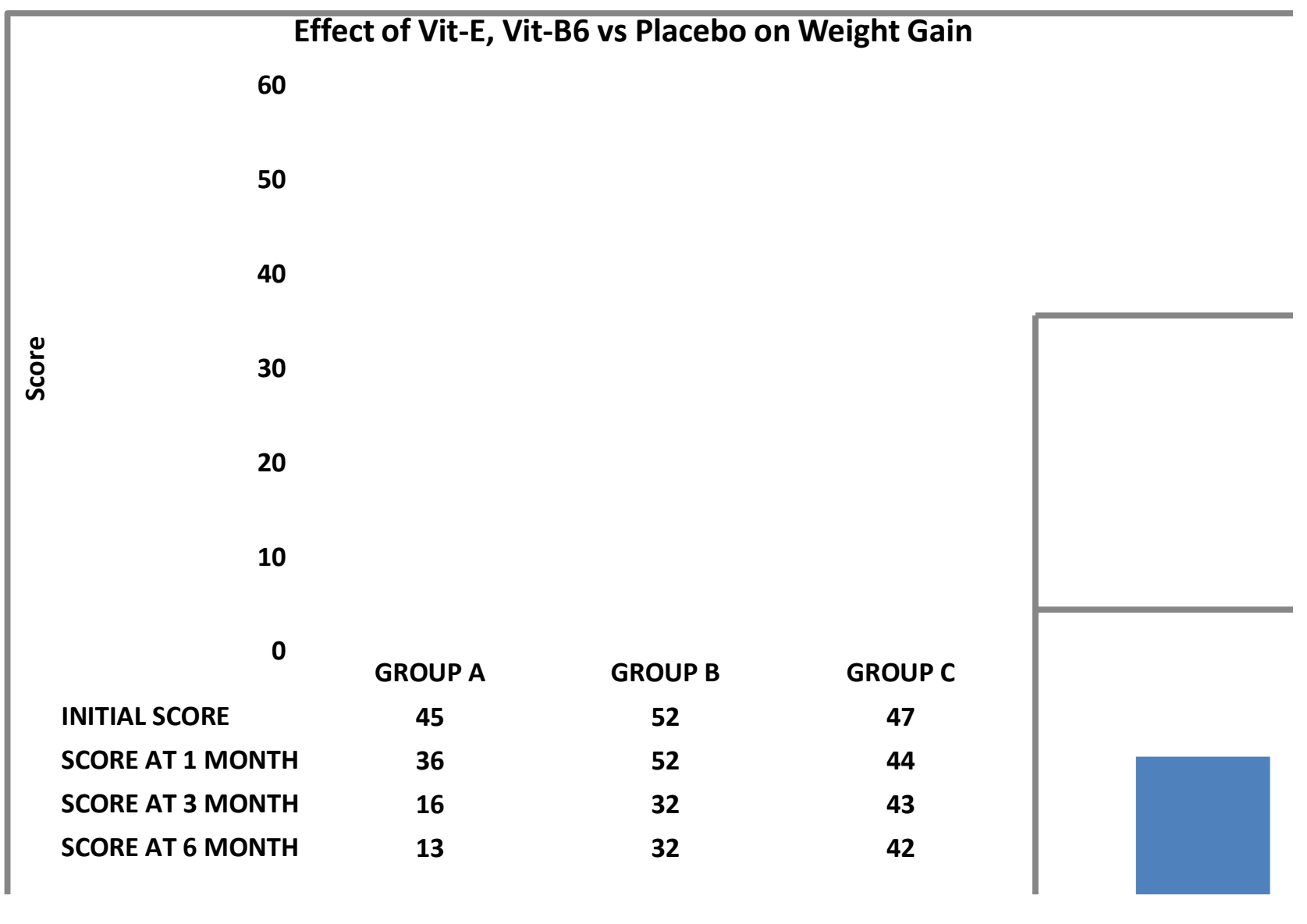

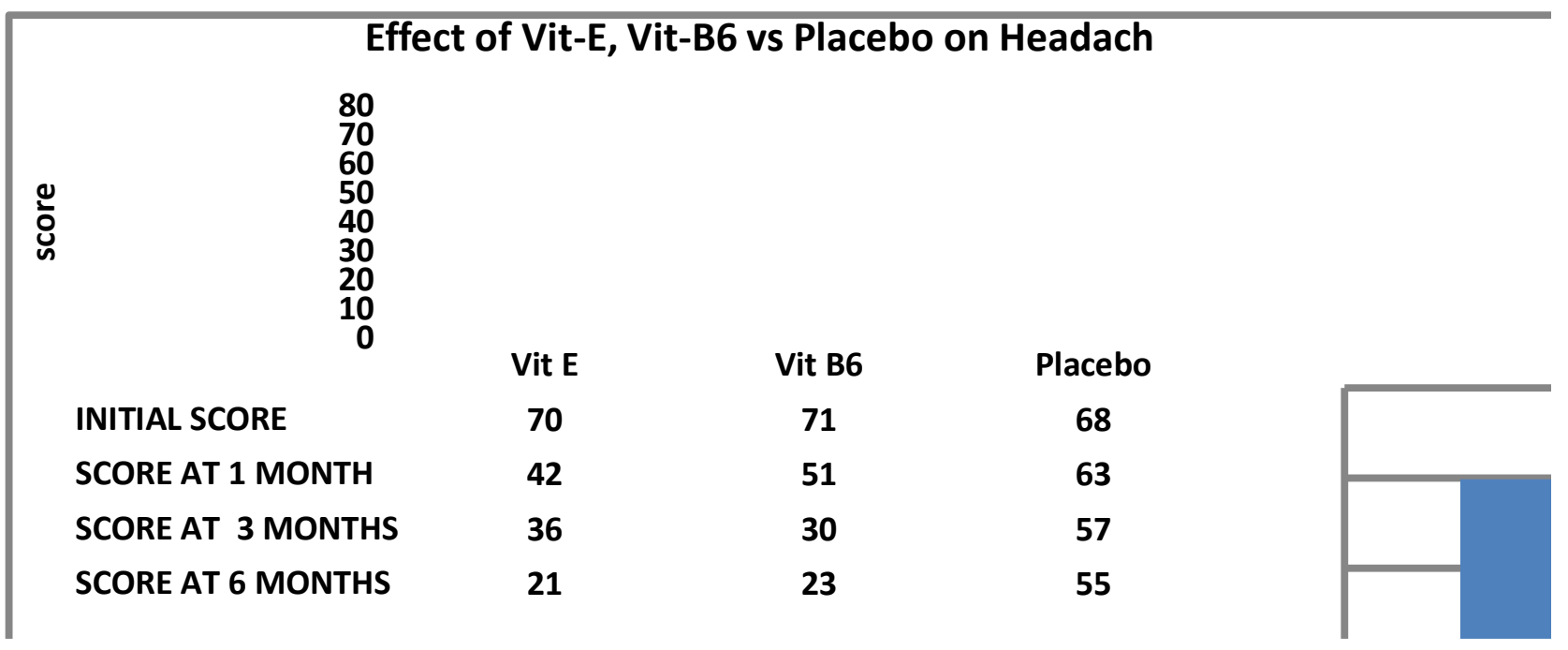




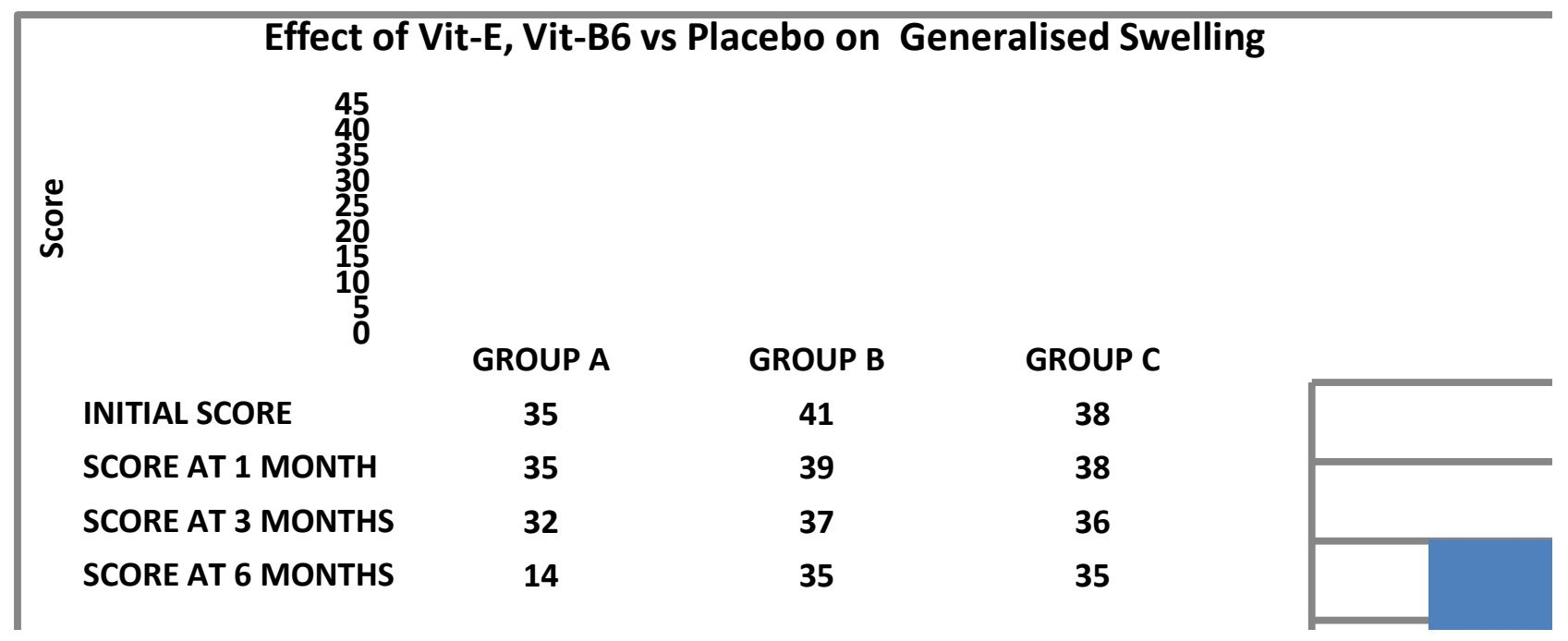

\begin{tabular}{|c|c|c|c|}
\hline \multicolumn{4}{|c|}{ Effect of Vit-E, Vit-B6 vs Placebo on Breast Tenderness } \\
\hline 60 & & & \\
\hline 50 & & & \\
\hline 40 & & & \\
\hline 30 & & & \\
\hline 20 & & & \\
\hline 10 & & & \\
\hline 0 & Vit E & Vit B6 & Placebo \\
\hline INITIAL SCORE & 51 & 46 & 49 \\
\hline SCORE AT 1 MONTH & 36 & 38 & 47 \\
\hline SCORE AT 3 MONTHS & 14 & 20 & 45 \\
\hline SCORE AT 6 MONTHS & 7 & 15 & 43 \\
\hline
\end{tabular}

\begin{tabular}{|c|c|c|c|}
\hline & ect of Vit- & B6 vs Plac & n Acne \\
\hline 25 & & & \\
\hline 20 & & & \\
\hline 15 & & & \\
\hline 10 & & & \\
\hline 5 & & & \\
\hline 0 & GROUP A & GROUP B & GROUP C \\
\hline SCORE AT 1 MONTH & 23 & 17 & 18 \\
\hline SCORE AT 3 MONTHS & 9 & 16 & 16 \\
\hline SCORE AT 6 MONTHS & 5 & 16 & 12 \\
\hline
\end{tabular}



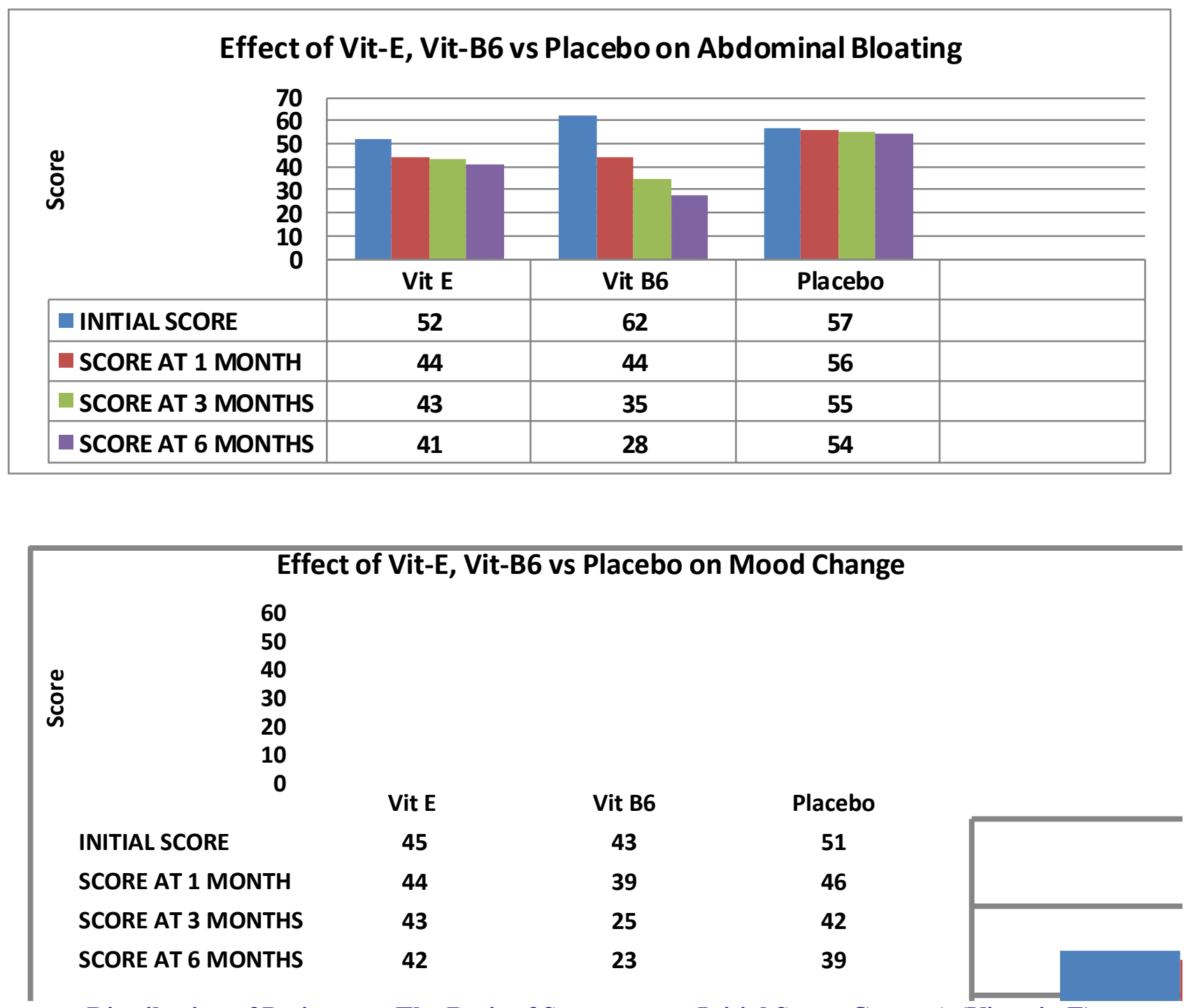

Distribution of Patients on The Basis of Symptoms at Initial Stage, Group A (Vitamin E)

\begin{tabular}{|c|c|c|c|c|c|}
\hline & SCORING & $\begin{array}{ll}\text { NO } & \text { SYMPTOMS } \\
(0) & \\
\end{array}$ & MILD (1) & $\begin{array}{l}\text { MODERATE } \\
\text { (2) }\end{array}$ & $\begin{array}{l}\text { SEVERE } \\
\text { (3) }\end{array}$ \\
\hline 1. & HEADACHE & - & & 20 & 10 \\
\hline 2. & WEIGHT GAIN & 1 & 13 & 16 & - \\
\hline 3. & $\begin{array}{l}\text { GENERALISED } \\
\text { SWELLING }\end{array}$ & 5 & 15 & 10 & - \\
\hline 4. & ACNE & 16 & 4 & 8 & 2 \\
\hline 5. & $\begin{array}{l}\text { BREAST } \\
\text { TENDERNESS }\end{array}$ & 2 & 9 & 15 & 4 \\
\hline 6. & $\begin{array}{l}\text { ABDOMINAL } \\
\text { BLOATING }\end{array}$ & - & 11 & 16 & 3 \\
\hline 7. & MOOD CHANGES & 1 & 16 & 10 & 3 \\
\hline
\end{tabular}


In another study carried out by Bertone-Johnson et al., on the effect of vitamin $\mathrm{E}$ and placebo on PMS, it was demonstrated that vitamin $\mathrm{E}(100 \mathrm{mg} /$ day $)$ and placebo had a similar effect on syndrome severity. ${ }^{[1]}$

London et al., also conducted a study on vitamin E and placebo in 1987. They reported that using $400 \mathrm{IU}$ ofvitamin E can alleviate the symptoms of PMS, but no significant difference was found between the twogroups. ${ }^{[12]}$ Also, Dolatian et al., assessed the effectiveness of vitamin E, vitamin B6, and placebo on PMS in 93patients in Tehran. They found that $100 \mathrm{mg}$ of vitamin E, $40 \mathrm{mg}$ of vitamin B6, or placebo, all had asimilar effect in the treatment of PMS. ${ }^{[13]}$ Pourmohsen $e t$ al., in their study on the effect of calcium, vitamin E, and placebo, reported that after 3 months of intervention with $1000 \mathrm{mg}$ of calcium plus $400 \mathrm{IU}$ of vitamin E, the severity of symptomsshowed a significant decrease in the intervention versus placebo group. ${ }^{[14]} \mathrm{A}$ current $\mathrm{RCT}$ suggests that the mean score of the syndrome significantly decreased in all the three groups $(12,16$, and 8 participants had decreased scores in vitamin $\mathrm{D}$, vitamin $\mathrm{E}$, and placebo, respectively). The differences between groups were not significant $(\mathrm{P}>0.05)$. But maximum effect was observed in Vit-E group. ${ }^{[15]}$ A more recent larger RCT though suggests that In group that, received Vit E, had significant difference after treatment; regarding their physical symptoms $(p=0.000)$, mental symptoms $(0.001)$ and theirphysical \& mental symptoms $(0.000) \cdot{ }^{[16]}$

The symptom score of group A and B has significant reduction over group $\mathrm{C}$, hence it is beneficial to give vitamin $\mathrm{E}$ and $\mathrm{B} 6$ for reducing the symptoms of premenstrual syndrome over placebo treatment. Results for comparison in groups A and B were insignificant. Vitamin E and B6 were equally effective for the improvement in symptoms of premenstrual syndrome. Last but not the least, all the patients suffering from PMS should inherent certain changes in their lifestyle such as taking healthy diet and exercising.

\section{References}

1. O'Brien PMS. Helping women with premenstrual syndrome. BMJ1993;307:1471-5.

2. Smith R, Studd J. Premenstrual syndrome. Clin Rev Gynaecol1994;939-47.

3. Chakmakjian ZH. A critical assessment of therapy for the premenstrualtension syndrome. $\mathrm{J}$ Reprod Med 1983;28:532-8.
4. Katrina M Wyatt, Paul W Dimmock, Peter W Jones, P M Shaughn O'Brien. Efficacy of vitamin B-6 in the treatment of premenstrualsyndrome: systematic review. BMJ 1999;318:1375-81.

5. Stokes J, Mendels J. Pyridoxine and premenstrual tension.Lancet 1972; 1: 1177-1178.

6. Mattes JA, Martin D. Pyridoxine in premenstrual depression. HumNutrApplNutr 1982: 36A: 131133.

7. Helen Doll, Susan Brown, Amanda Thurston,Martin Vessey. Pyridoxine (vitamin B6) and thepremenstrualsyndrome: a randomized crossover trial. Journal of the Royal College of General Practitioners, 1989, 39,364-368.

8. Hagen I, Nesheim B-I, Tuntland T. No effect of vitamin B6against premenstrual tension: a controlled clinical study. Acta Obstet GynecolScand 1985; 64: 667-670.

9. Kendall KE, Schnurr PP. The effect of vitamin B6supplementation on premenstrual symptoms. ObstetGynecol 1987;70: 145-149.

10. Abraham GE, Hargrove JT. Effect of vitamin B6 on premenstrual symptomatology in women with premenstrual tension syndrome: a double blind crossover study. Infertility 1980; 3: 155-165.

11. Johnson SR. Clinician's approach to the diagnosis and management of premenstrual syndrome. ClinObstet Gynecol. 1992; 35:637-57.

12. London RS, Murphy L, Kitlowski KE, Reynolds MA. Efficacy of alpha-tocopherol in the treatment ofthe premenstrual syndrome. J Reprod Med. 1987; 32:400-4.

13. Dolatian M, Montazeri SH, Velaei N, Ahmadi M. Comparative effects of vitamin B6 and vitamin E onsymptoms of premenstrual syndrome. J ZanjanUniv Med Sci. 2002;37:5-10.

14. Pourmohsen M, Zoneamat KA, Taavoni S, Hosseini AF. Effect of combined calcium and vitamin Econsumption on premenstrual syndrome. J Iran Nursing Tehran Univ Med Sci Health Services. 2010;23:8-14

15. Hajar Dadkhah, Elham Ebrahimi, and NahidFathizadeh. Evaluating the effects of vitamin $\mathrm{D}$ and vitamin $\mathrm{E}$ supplement onpremenstrual syndrome: A randomized, 
double-blind, controlled trial.Iran J Nurs Midwifery Res. 2016 Mar-Apr; 21(2): 159-164.

16. Zafari Mandana, Aghamohammady Azar, and
Vitamin E on Treatment of Premenstrual Syndrome: AClinical Randomized Trial. Journal of Medical and Health Sciences.September 2013.

Tahmasebi Homeira. Evaluation the Effect of

How to cite this article:

Shikha Singh, Rekh Rani, Asha, Ragini and Divya Yadav Sharma. 2017. A Prospective Randomised Trial to Study the Efficacy of Vitamin B6 (Pyridoxine) and Vitamin E in Patients of Premenstrual Syndrome. Int.J.Curr.Res.Aca.Rev. 5(9), 15-21. doi: https://doi.org/10.20546/ijcrar.2017.509.003 